\title{
Further information and useful resources
}

\section{NSW Premier's Council for Active Living}

The NSW Premier's Council for Active Living (PCAL) aims to strengthen physical and social environments to enable active living. The PCAL comprises representatives from government agencies, business and the community sector. It was established in 2004, building on the work of the NSW Physical Activity Taskforce from 1996 and reports to the Premier through the Minister for Health. PCAL's priorities include healthy urban planning, community inclusion and the liveability of NSW cities and towns. It provides advice to government and promotes guidelines, policy, and legislation to increase the level of physical activity of all people in NSW.

Designing Places for Active Living is a free PCAL web-resource which provides design considerations for walking and cycling routes, public transport, streets, open spaces and shopping centres as well as links to references and other resources for more detailed guidelines and specifications. The resource is directly applicable for strategic planning, transport planning, road and traffic design, open space recreation planning and health planning. Further information is available at www.pcal.nsw.gov.au.

\section{World Health Organization's Healthy Cities program}

The World Health Organization's Healthy Cities program engages local governments in health development through a process of political commitment, institutional change, capacity building, partnership-based planning and innovative projects. It has a special emphasis on health inequalities and urban poverty, the needs of vulnerable groups, participatory governance and the social, economic and environmental determinants of health. Healthy Cities is a global movement, with networks in all six WHO regions. Further information and resources are available from www.euro.who.int/healthy-cities.

\section{World Health Organisation Centre for Health Development, Kobe Japan}

Over the next ten years, the research programme of the WHO Kobe Centre is focussed on urbanization and health equity. Through its project on "Healthy Urbanization: Optimizing the impact of social determinants of health on exposed populations in urban settings", the Centre will contribute to the generation of new knowledge and stimulate action to confront the issue of health inequity in urban settings in both developing and developed countries. For further details of the field research sites see http://www.who.or.jp/sites/sites.html.

\section{US Centers for Disease Control and Prevention's Healthy Places initiative}

The Centers for Disease Control Healthy Places initiative supports the design and development of healthy environments. The Centers for Disease Control facilitates a Listserv that addresses issues related to health and the built environment. A regular e-newsletter that includes relevant news articles, latest research, other publications, and updates on conferences and events related to liveability is sent to all subscribers. Further information and resources, including details of how to join the Listserv, are available from www.cdc.gov/healthyplaces.

\section{Active Living by Design}

Active Living by Design is a program of the Robert Wood Johnson Foundation, based at the School of Public Health, University of North Carolina at Chapel Hill. The program establishes innovative approaches to increase physical activity through community design, public policies and communications strategies. Further information and resources are available from www.activelivingbydesign.org.

\section{Sustain}

Based in London, Sustain advocates food and agriculture policies and practices that: enhance the health and welfare of people and animals; improve the working and living environment; promote equity; and enrich society and culture. It represents around 100 public interest organisations working at international, national, regional and local level. Among other roles, Sustain advises and negotiates with governments and other regulatory agencies to ensure that legislation and policies on food and agriculture are publicly accountable and socially and environmentally responsible. Its website contains research reports, popular publications and details of community campaigns: http://www.sustainweb.org/.

\section{The Slow Cities movement}

This movement consists of cities that are committed to improving the quality of life of their citizens, especially with regard to food issues. Slow Cities are cities which implement an environmental policy designed to maintain and develop the characteristics of their surrounding area and urban fabric, placing the onus on recovery and reuse techniques. They encourage the production and use of foodstuffs produced using natural, eco-compatible techniques, excluding transgenic products, and setting up, where necessary, presidia to safeguard and develop typical products under threat of extinction. Further information is available from www.matogmer.no/slow_cities_citta_slow.htm.

\section{David Mason's blog}

The blog began as a diary of an eight week international study tour of urban agriculture undertaken as a Winston Churchill Fellow. The website is being developed as an international point of reference for those interested in agriculture in urban and urbanising environments. It is structured to provide a systemic appreciation of urban agriculture. See the useful linkages and resources at http://www.urbanagricultureworldwide.com/.

Also see the website for the Resources Centres on Urban Agriculture \& Food Security http://www.ruaf.org/. 